direction for cancer prevention campaigns. A significant proportion considered both traffic fumes and microwaves to be risk factors. Although scientific evidence does not support these, both have also had considerable media coverage. How this can be countered is less clear: some of the population distrust much of the information they receive from 'official' sources. ${ }^{5}$ Maybe these erroneous cancer beliefs are less important at an individual level - as avoidance of microwaves or traffic fumes is very unlikely to be harmful.

\section{Jenny Knowles}

Programme Director and National Lead: Healthy Communities, Improvement Foundation, First Floor, Gateway House, Piccadilly South, Manchester, M60 7LP.

\section{William Hamilton}

Consultant Senior Lecturer, Academic Unit of Primary Health Care, University of Bristol, 25 27, Belgrave Road, Bristol BS8 4AA. E-mail: w.t.hamilton@btopenworld.com

\section{REFERENCES}

1. Sasco AJ, Secretan MB, Straif K. Tobacco smoking and cancer: a brief review of recent epidemiological evidence. Lung Cancer 2004; 45(Suppl 2): S3-S9.

2. Danaei G, Vander Hoorn S, Lopez AD, et al. Causes of cancer in the world: comparative risk assessment of nine behavioural and environmental risk factors. Lancet 2005; 366(9499): 1784-1793.

3. Breast Cancer Campaign. Awareness of breast cancer risk factors low, 2007. http://www.breastcancercampaign.org/mediacentre/ne ws/96/ (accessed 7 Aug 2008).

4. Wardle J, Waller J, Brunswick N, Jarvis M. Awareness of risk factors for cancer among British adults. Public Health 2001; 115(3): 173-174

5. O’Neil O. A Question of Trust. Cambridge: Cambridge University Press, 2002.

DOI: 10.3399/bjgp08X342039

\section{Family medicine in China}

The paper in this journal ${ }^{1}$ made a full description on the past, present, and future of family medicine education and training in China. With regard to the future, the authors suggested that the Chinese National Degree Council should set up an application system of speciality family medicine for Masters Degrees and Doctors Degrees as soon as possible. Currently this suggestion has been adopted by some leading universities in the field of family medicine education in China, for example, Zhejiang University School of Medicine initiated establishing this in 2008. Students and researchers having Bachelors Degrees in public health and clinical medicine can apply for Masters Degrees in Family Medicine if they are qualified, that is having enough credit hours, publishing academic papers in peer-reviewed journals, and passing an oral examination. Likewise, students and researchers having a Masters Degree in the aforementioned field can apply for a Doctors Degree in Family Medicine if they are qualified in the above aspects. The establishment of this application system is very important for the sustainable development of family medicine in China. The future of family medicine education in China will be very promising.

\section{Tianhui Chen}

PhD, Institute of Social Medicine and Family Medicine, Zhejiang University, China. Email: cth006@hotmail.com

\section{REFERENCE}

1. Chen TH, Du YP, Sohal A, Underwood M. Family medicine education and training in China: past, present and future. Br J Gen Pract 2007; 57(541): 674-676.

DOI: 10.3399/bjgp08X342048

\section{Alford's theoretical work}

Charlotte Williamson's piece on Alford's theoretical political model ${ }^{1}$ provides a seductive analysis which she is applying to the flux happening now within health service organisation in the UK. However it should be acknowledged that this is a political theory. By describing clinician's interests as 'dominant', the use of language alone implies that their interest should be moderated or brought down.

Alford developed his theory to effect change in 1970s US health care, when many could agree clinician's interests may be entrenched for financial reasons.

However, I would argue that what motivates clinicians who have grown up in, been trained in, and who work in the NHS of the UK is quite different. Williamson alludes to professional monopolists believing altruism as a motivator. I would argue this is a truth rather than a belief. Going the extra mile for the patient, or staying on the extra hour to sort out a problem, demonstrates the beneficence of the clinician and nurtures the relationship for the patient. This is a marker of quality that I have yet to see quantified or put into the equation when it comes to advocating change. It is integral with a sense of ownership of the system by the clinician. Clinicians know it is in the best interests of the patient (and indeed a silent majority of patients know this also).

When clinicians are seen as resistant to change it needs to be borne in mind they are so when they can see a system that works being eroded. The type of personality that is attracted to medicine is not the same as the businessman. When describing our interest as 'dominant', it is not the money that it is making us resist change, it is the preservation of a system whereby we can feel good about doing good. Individual patients see the benefit of this every day. Politicians need to understand how fundamental this is to the whole business of doctors treating patients to the satisfaction of all concerned. And when doctors are seen as resisting change, we need to shout loudly that it is not because of conservatism (with which so may find convenient to label us), but because we are and always have been radical advocates of out patients interests.

\section{Mark Freeman}

Churchwood Medical Practice, Tilebarn Road, St Leonards-on-sea East Sussex, TN38 9QU. E-mail: mark.freeman@nhs.uk

\section{REFERENCE}

1. Williamson C. Alford's theoretical political framework and its application to interests in health care now. $\mathrm{Br} \mathrm{J}$ Gen Pract 2008; 58(522): 512-516.

DOI: 10.3399/bjgp08X342156 